\title{
Siyasal İndikatörlerin Ermenistan-İran İlișsileri Örneğinde Uygulanması
}

\section{The Using of Political Indicators in the Example of Armenia-Iran Relations}

\author{
Elnur Kelbizadeh ${ }^{1}$
}

'Sorumlu yazar/Corresponding author: Elnur Kelbizadeh (Dr. Öğretim Üyesi), Azerbaycan Milli Bilimler Akademisi Kafkasya Araștırmaları Enstitüsü Kafkasya Politikası Bölümü, Bakü, Azerbaycan E-posta: kelbizadeh@gmail.com ORCID: 0000-0001-5870-034X

Başvuru/Submitted: 16.05 .2020 Kabul/Accepted: 11.08 .2020

Atıf/Citation: Kelbizadeh, Elnur. "Siyasal Indikatörlerin Ermenistan-Iran Ilișkileri Örneğinde Uygulanması.", Avrasya Incelemeleri Dergisi - Journal of Eurasian Inquiries 9, 2 (2020): 247-257.

https://doi.org/10.26650/jes.2020.016

\section{ÖZ}

Uluslararası sistemin aktörleri (devletler, devletlerüstü ve uluslararası örgütler vb.) arasındaki ilişkilerin geliştirilmesi bir süreç olduğundan, belirli değerlendirme kriterlerinin - indikatörlerin tanımlanmasına ihtiyaç vardır. Farklı devletler arasındaki ilişkileri inceleyen araştırmacılar, çoğu durumda ciddi krizler olmadıkça ilişkileri sıklıkla belirli bir kronolojik çerçevede "gelişen ilişkiler" olarak tanımlarlar. Bununla birlikte, ciddi krizler kendini göstermediğinde, bu tür ilişkiler çeşitli faktörlere bağıı olarak gelişebilir veya zayıflayabilir. Bu açıdan bakıldığında, devletler de dahil olmak üzere uluslararası ilişkiler sisteminin aktörleri arasındaki ilişkilerin gelişimini ve düşüşünü bilimsel yöntemlerle değerlendirmek için indikatörlerin - uluslararası ilişkilerin değerlendirilmesinin göstergelerinin tanımlanması gerekmektedir. Ortalama olarak, devletlerarası ilişkilerin hareketini değerlendirmek için kullanılan yaklaşık yüze kadar indikatörü tanımlamak mümkündür. Bununla birlikte, bu indikatörlerin gruplandırılması sistematik bir analiz yapmak için önemli koşullardan biridir. Bu anlamda devletlerarası ilişkilerin yönünü belirlemek için kullanılan göstergeler üç gruba ayrılabilir: Siyasal indikatörler, Ekonomik indikatörler, Sosyal indikatörler.

Makalede başlıca siyasal indikatörler Ermenistan Cumhuriyeti ile İran İslam Cumhuriyeti arasındaki ilişkiler örneğinde pratik uygulamalarla tanımlanmıştır. Iki ülke arasında ilişkilerin değerlendirilmesi için üst düzey yetkililerin (cumhurbaşkanı ve başbakanlar) ziyaretlerinin sayısı, yabancı ülkelerde ve uluslararası kuruluşların toplantılarında üst düzey temsilcileri arasında temaslar, dış politikadan sorumlu kurumların karşılıklı ziyaretlerinin, istişarelerinin sayısı ve seviyesi, ilki ülke arasında imzalanan belgelerin sayısı ve kapsamı ile imza sahiplerinin yönetim sistemindeki yeri və b. indikatörler kullanılımıştır.

Anahtar kelimeler: Uluslararası ilişkiler, İndikatör (gösterge), Ermenistan, İran

\section{ABSTRACT}

Since the development of relationships between the subjects of the international system (between states, between states and international organizations, between international organizations, etc.) is necessary and certain evaluation criteria (indicator indicators) should be determined. Researchers, who examine the relations between various states, often describe the relations as "developing 
relations" if there are no acute(sharp) crises in the chronological framework. However, in cases of serious crisis does not occur, such relationships can develop or weaken due to various factors. In this respect, it is imperative to determine indicators (evaluation indicators of international relations) to evaluate the periods of development and decline of relations with scientific methods between states, including participants (subjects) of the international relations system. It is possible to have up to an average of hundred indicators used to evaluate the movement of interstate relations. However, grouping these indicators is one of the important conditions for conducting a systematic analysis. In this sense, it is possible to divide the indicators used to determine the direction of action of interstate relations into three groups: Political indicators, Economic indicators and Social indicators.

For the first time, it has been tried to determine main political indicators in the science of international relations and to apply them in the example of the relations between the Republic of Armenia and the Islamic Republic of Iran. For evaluation of the relations between the two countries an main indicators used the number of reciprocal visits at the level of heads of state and government, the number of meetings held by the senior representatives of the two countries in foreign countries and within the framework of the meetings of international organizations, number and rate of mutual expeditions of managers of institutions responsible for foreign policy and number of disscussing ideas, the number, scope and place of the documents signed between the two countries in the state administration syste and etc. others.

Keywords: International relations, Indicator, Armenia, Iran

\section{EXTENDED ABSTRACT}

Since development of relationships between the subjects of the international system (between states, between states and international organizations, between international organizations, etc.) is necessary and certain evaluation criteria (indicator/indicators) should be determined. Researchers, who examine the relations between various states, often describe them as "developing relations" if there is no acute(sharp) crisis in the chronological framework. However, in cases where serious crisis does not occur, such relationships can develop or weaken due to various factors. In this respect, it is imperative to determine indicators (evaluation indicators of international relations) to evaluate the periods of development and decline of relations with scientific methods between states, including participants (subjects) of the international relations system.

Some researchers, such as Russian researchers M.A. Timopheyeva, M.G. Vlasova, N.V. Derugin, N. Bistrov, R. Vexman and others have mentioned the importance of an indicators intelligence and prognosis of international relations. In his study on the application of mathematical methods in the study of international relations, I. Mikheyev analyzed methods of indicators. M.G. Vlasova defined the concept of an indicator as follows: "Indicators are events that are observed as an indicator of the movement of a particular process or scenario". However, Indicators spoke more about security and defense than indicators of interstate relations.

Research allows the following concrete definition for the concept of indicator in interstate relations: "Indicators that allow to evaluate the movement of relations between the subjects in the system of international economic relations within a specific time frame". 
It is possible to have up to an average of hundred indicators used to evaluate the movement of interstate relations. However, grouping these indicators is one of the important conditions for conducting a systematic analysis. In this sense, it is possible to divide the indicators used to determine the direction of action of interstate relations into three groups: Political indicators, Economic indicators and Social indicators.

For the first time, it has been tried to determine the main political indicators in the science of international relations and apply them in the example of relations between the Republic of Armenia and the Islamic Republic of Iran. The direction of development and decline of relations between the Republic of Armenia and the Islamic Republic of Iran in the political arena is determined by using the following indicators:

1) The number of reciprocal visits at the level of heads of state and government within the chronological framework;

2) The number of meetings held by the senior representatives of the two countries in foreign countries and within the framework of the meetings of international organizations;

3) Number and rate of mutual expeditions of managers of institutions responsible for foreign policy and number of ideas disscussed;

4) Overlapping of authorities in the decision making process in international organizations and supporting the proposed projects;

5) The number, scope, and place of the documents signed between the two countries in the state administration system.

6) Level of inter-parliamentary relations and approval frequency (amplitude) of bilateral agreements signed.

7) Paying special attention to the other country in the government's activity programs.

Analysis shows that it is possible to successfully apply the indicator method as a way of learning interstate relations in modern conditions. Only in this case, the theses put forward to develop, maintain, or decline interstate relations can be considered scientifically objective.

A few points need to be clarified here. First of all, there should be indicators to determine the nature of the movement of interstate relations (development and decline). Second, these indicators should be applied to interstate relations in a concrete time frame. Third, evaluations for the indicators received can show the character of the movement, the progress, and decline only if the researcher has the opportunity to compare the same demonstrators with data set in another time frame. 


\section{Giriş}

İstihbarat ve uluslararası ilişkilerin geleceğine yönelik tahmin ve öngörmelerde indikatörlerin önemi rus araştırmacılar M.A.Timofeyeva ${ }^{1}$, M.G.Vlasova ${ }^{2}$ N.V.Deryuqin, N.Bystrov, R.Wexman ve diğerleri de dahil olmak üzere bir dizi araştırmacı tarafından tartışıldı. Uluslararası ilişkilerin araştırılmasında matematiksel yöntemlerin uygulanması üzerine yaptığı çalışmada İ.Mikheyev indikatörler yöntemine değindi. ${ }^{3}$ M.Vlasova indikator - gösterge kavramını şu şekilde tanımlamıştır:

“Göstergeler, belirli bir sürecin veya senaryonun hareketinin bir göstergesi olarak gözlenen olaylardır". 4

Ancak, belirtmek gerekir ki, M.Vlasova devletlerarası ilişkilerin indikatörlerinden daha fazla güvenlik ve savunma göstergeleri üzerine yoğunlaşmış ve onları araştırmıştır.

Araştırmalarımız sonucu uluslararası ilişkilerde indikator (gösterge) kavramını şu şekilde tanımlaya biliriz: "İndikatörler, belirli bir zaman dilimi içinde uluslararası ilişkiler sisteminin aktörleri arasındaki ilişkilerin hareketini değerlendirmeyi sağlayan göstergelerdir”. Burada birkaç noktanın açıklığa kavuşturulması gerekiyor. Her şeyden önce, devletlerarası ilişkilerin hareketinin doğasını (gelişme ve düşüş) belirleyen göstergeler olmalıdır. İkinci olarak, bu göstergeler, belirli bir zaman dilimi içinde devletler arası ilişkilere uygulanmalıdır. Üçüncüsü, alınan göstergelerin değerlendirmeleri, araştırmacının aynı göstergeleri başka bir zaman diliminde tanımlananlarla karşılaştırma firsatı bulduğunda, hareketin doğasını (ilerleme veya düşüş) gösterebilir.

Bazen, devletlerarası ilişkilerin gelişim düzeyini belirlemek için, araştırmacılar iki ülke arasındaki ilişkileri üçüncü ülkelerle olan mevcut ilişkilerle karşılaştırmaktadır. Örneğin, Azerbaycan Cumhuriyeti ile İran İslam Cumhuriyeti arasındaki ilişkileri İran-Ermenistan ilişkileriyle, Azerbaycan Cumhuriyeti ile İsrail arasındaki ilişkileri Ermenistan-İran ilişkileriyle karşılaştırmak mümkündür. Bununla birlikte, bu karşılaştırmalar iki devlet arasındaki ilişkilerin gelişimini ve ya düşüşünü belirlemek için nesnel bir indikatör olarak kabul edilemez.

\section{İndikatörlerin Sınıflandırılması}

Ortalama olarak, devletlerarası ilişkilerin hareketini değerlendirmek için kullanılan yaklaşık yüze kadar indikatörü tanımlamak mümkündür. Bununla birlikte, bu indikatörlerin

1 Марина Тимофеева, “Опыт политического прогнозирования в США и России” [“Рolitical Forecasting Experience in the USA and Russia"]. (Автореферат диссертации на соискание учено степени кандидата политических наук. Санкт-Петербургски Государственный Университет, 2005), 14.

2 Мария Власова, «Прогнозирование в разведке: метод индикаторов в современных условиях» [Intelligence forecasting: a method of indicators in modern conditions], Вестник РУДН, серия Международнье отношения, том 15/3 (сентябрь 2015): 35

3 Игорь Михайлович, Применение математических методов при исследовании системы международных отношений с использованием функциональных пространств [The use of mathematical methods in the study of the system of international relations using functional spaces]. (Москва, 1997). 
gruplandırılması sistematik bir analiz yapmak için önemli koşullardan biridir. Bu anlamda devletlerarası ilişkilerin yönünü belirlemek için kullanılan göstergeler üç gruba ayrılabilir:

1. Siyasal indikatörler;

2. Ekonomik indikatörler;

3. Sosyal indikatörler.

Devletler arasındaki ilişkilerin hareketini belirlemek için en önemli indikatörler siyasal göstergelerdir. Temel siyasal indikatörler - iki ülke arasındaki devlet ve hükümet yetkilileri düzeyinde ziyaretlerin sayısı, en üst düzey ziyaretlerin sayısı, imzalanan anlaşmaların sayısı, hükümetler arası ve hükümetler arası komisyonların toplantılarının yoğunluğunu, farklı devlet kurumları arasındaki ortak projelerin sayısı, uluslararası örgüt ve kuruluşlardaki pozisyonların karşılaştırılması ve başkalarıdır.

Önemli ekonomik indikatörler ülkeler arasındaki ticaret cirosu hacmini, bir ülkenin diğerinin ekonomisine yaptığ 1 yatırımların hacmini, ithalat-ihracat operasyonlarının hacmini, ekonomik projelerin yoğunluğunu ve b. göstergeleri içerir.

Devletler arasındaki ilişkilerin yönünü belirlemek için sosyal indikatörler de önemlidir. Sivil toplum örgütleri, dini kuruluşlar, medya, iki ülke vatandaşlarının yakınlığı (işbirliği, akrabalık vb.), vatandaşların karşılıklı ziyaretleri, diaspora ve lobi gruplarının faaliyetlerinin ölçeği önemli sosyal göstergelerdir. Örneğin, bir ülkenin vatandaşlarının başka bir ülkede eğitim görmesi, çalışması, yatırımları ve banka hesaplarının olması, akrabalık bağlarının olması devletler arasındaki ilişkiler üzerinde olumlu bir etkiye sahip olabilir.

\section{Siyasal İndikatörlerin Uygulanması}

Politik ilişkilerin gelişim ve gerilemesi aşağıdaki siyasal indikatörler kullanılarak belirlenebilir:

1) Belirlenmiş kronolojik çerçevede üst düzey yetkililerin (cumhurbaşkanı ve başbakanlar) ziyaretlerinin sayıs1;

2) İki ülkenin üst düzey temsilcileri arasında yabancı ülkelerde ve uluslararası kuruluşların toplantıları çerçevesinde yapılan ikili görüşmelerin sayısı;

3) Dış politikadan sorumlu kurumların karşılıklı ziyaretlerinin, istişarelerinin sayısı ve seviyesi;

4) Uluslararası kuruluşlarda karar alma sürecindeki pozisyonların çakışması ve önerilen projelerin desteklenmesi;

5) İki ülke arasında imzalanan belgelerin sayısı ve kapsamı ile imza sahiplerinin yönetim sistemindeki yeri;

6) Parlamentolar arası ilişkilerin düzeyi ve imzalanan ikili anlaşmaların onaylanma sıklığı (genliği);

7) Hükümetlerin eylem planlarında diğer ülkelere özel dikkat.

İki ülke arasındaki ilişkilerin gelişim yönünü (gelişme, gerileme veya istikrar), ele almak 
için öncelile ilişkilerdeki kronolojik çerçeveler - dönemler, aşamalar vb. belirlenmelidir. Belirli bir kronolojik çerçevedeki istatistikleri diğer dönemlerle karşılaştırabilmek için bu gereklidir. Yukarıda belirtildiği gibi, bazı durumlarda, nesnel bilimsel sonuçların elde edilmesine izin vermeyen ve öznel sonuçlara yol açan devleterarası ilişkilerin gelişim seviyesini belirlemek için üçüncü bir ülke ile karşılaştırmalar yapılır. Her şeyden önce, üç ülke arasındaki ikili ilişkilerin aşamaları kronolojik olarak çakışmayabilir. İkincisi, devletler arasındaki ilişkiyi belirleyen faktörler (coğrafi yakınlık, tarihsel gelenekler, dil, din vb.) aynı olmayabilir. Bu açıdan, Ermenistan ile İran İslam Cumhuriyeti arasındaki ilişkileri incelemek için ilk gösterge, devlet ve hükümet başkanları düzeyinde, belirli kronolojik çerçevelerde karşılaştırılabilecek karşılıklı ziyaretlerin sayısıdır. Örneğin, 1991-1997 yılları arasında Ermenistan'dan devlet ve hükümet başkanları düzeyinde İran İslam Cumhuriyeti'ne yapılan ziyaret sayısı 4 (başkan düzeyinde 3, başbakan düzeyinde 1), İran İslam Cumhuriyeti'nden Ermenistan'a ziyaret sayısı sadece 1'dir (başkan yardımcısı düzeyinde). Toplamda, bu sayı 5 ziyaretle sınırlıdır. 1998-2008'de Ermenistan'dan İran İslam Cumhuriyeti'ne yapılan bu tür ziyaretlerin sayısı 2 (başkanlık düzeyinde) ve İran İslam Cumhuriyeti'nden Ermenistan'a yapılan ziyaretlerin sayısı 3 'tür (başkanlık düzeyinde). ${ }^{5} \mathrm{Genel}$ olarak, bu dönemde iki ülke arasındaki üst düzey karşılıklı ziyaret sayısı 5 'tir.

Ancak ilk başta Ermenistan'ın İran'la ilişkileri güçlendirmekle ilgilendiği ve İran'ın yeni uluslararası ortamda daha temkinli olduğu gözlemlendi. Bu konu, Kafkas ülkelerinin bağımsızlığının ilk aylarında İran'ın Azerbaycan Cumhuriyeti ile ilişkiler kurmaya ve buradaki prestijini güçlendirmeye daha fazla önem vermesiyle de ilgiliydi. 1991-1996 yıllarında Ermenistan'dan İran İslam Cumhuriyeti'ne yapılan üst düzey ziyaretlerin çoğu, Azerbaycan topraklarının işgali sonucu ortaya çıkan Dağlık Karabağ çatışmasıyla ilgiliydi. Genel olarak, 1991'den beri bu göstergede yapılan karşılaştırmalardan, İran İslam Cumhuriyeti Başkanı Mahmud Ahmedinejad'ın Ermenistan ile ilişkilerin kurulmasına en fazla önem verdiği açıktır. Ermeni tarafında, Serzh Sarkisyan'ın yönetim yılları bu açıdan özellikle dikkat çekicidir. Bazı Ermeni siyasetçilerin gizli Yahudi nefretinin farkında olan Ahmedinejad hükümeti bu meseleden yararlanmaya çalıştı. Örneğin, Ekim 2005'te İran Cumhurbaşkanı Mahmud Ahmedinejad, “Siyonizmsiz Dünya” Konferansı'nda ABD, İsrail ve Yahudiler aleyhinde konuştu. Ermenistan'ın bu konudaki tutumuyla ilgili olarak, arşiv belgelerinden birinde şöyle yazıyor: "Ermeni yetkililer, "Siyonizmsiz Bir Dünya" konulu konferansta İran Cumhurbaşkanı Mahmud Ahmedinejad'ın İsrail ve ABD hakkındaki açıklamalarını çevreleyen gerilimler hakkındaki görüşlerini de dile getirdiler. Dışişleri Bakanı Vartan Oskanyan Erivan Devlet Üniversitesi öğretim üyeleriyle yaptı̆̆ 1 görüşmede "bu ifadenin İran-Ermenistan ilişkilerini etkilemeyeceğini" söyledi. ${ }^{6}$

Bu dönemde jeopolitik gerilimlerin iki ülke arasında daha yakın bağlara yol açtığına

5 "Bilateral Relations with Islamic Republic of Iran," Last accessed: 30 august, 2019, https://www.mfa.am/en/ bilateral-relations/ir/.

6 ARXINA, Qovluq 6, v. 26. 
dikkat edilmelidir. Her iki ülkenin de bölgedeki büyük projelere dahil edilmemesi, bu ülkelerin alternatif projeler uygulama hareketlerini arttırmıştır. Bu açıdan Ermenistan-İran ekonomik ilişkileri tarihindeki en önemli olaylardan biri, İran İslam Cumhuriyeti Cumhurbaşkanı Mahmud Ahmedinejad'ın Mart 2007'de Erivan'a yaptığı ziyaret sırasında gerçekleşti. 19 Mart 2007'de iki ülke arasında bir gaz boru hattı açıldı. Ermeni tarafı projeyi "enerji diplomasisi” alanında "büyük başarı" olarak nitelendirdi. ${ }^{8}$ Ve ya İran Cumhurbaşkanı Hassan Ruhani’nin yönetiminin ilk üç yılında Ermenistan ile siyasi alanda ilişkilerin ve tartışmaların azalması hakkında konuşmak mümkündür. Bu dönemde, İran İslam Cumhuriyeti’nden Ermenistana cumhurbaşkanlığ 1 düzeyinde hiçbir ziyaret yapılmamışdır. Ancak, Ağustos 2013'te Ermenistan Cumhuriyeti Cumhurbaşkanı Serzh Sargsyan, İran İslam Cumhuriyeti'ni ziyaret etti ve yeni seçilen İran İslam Cumhuriyeti Cumhurbaşkanı Hassan Ruhani'nin yemin törenine katıldı. ${ }^{9}$ Jeopolitik gerçekleri iyi anlayan, İran İslam Cumhuriyeti’nde “Diplomasi Şeyhi” olarak bilinen Hassan Ruhani, reformcu tutumuyla biliniyor ve Mahmud Ahmedinejad'ın aksine dış politikayı ırkçı sloganlarla karıştırmadı.

2014 yılının başında Ermenistan ile İran İslam Cumhuriyeti arasındaki ilişkiler daha da gerginleşti. Mesele, 2013'ün sonlarında Ermenistan ve Rusya Federasyonu'nun gaz ithalatı konusunda bir anlaşma imzalamasıydı. Bu anlaşmanın imzalanması, Rusya Federasyonu'nun İran-Ermenistan-Gürcistan güzergahı üzerinden İran gazını Avrupa pazarlarına alternatif olarak çıkmasını istemediği ve İran'ın genel olarak Ermenistan'a gaz ihracatını engellemeye çalıştığı anlamına geliyordu. Buna karşılık İran tarafı, Ermenistan'dan ithal edilen enerjiye ihtiyaç olmadığını ve bunun İran'ın Ermenistan'a dostane yardımı olduğunu belirtti. Ardından, İran cumhurbaşkanı Hassan Ruhani planlanan Ermenistan ziyaretini erteledi. İran tarafı çok yüksek düzeyde tartışılan İran-Ermenistan demiryolunun inşasının sorumluluğunu Ermenistan’a koyan bir açıklama yaptı. Sonuç olarak, 2015 yılında İran ve Ermenistan arasında en önemli projeler olarak kabul edilen Mehri Hidroelektrik Santrali, İran-Ermenistan demiryolu, rafineri ve üçüncü yüksek gerilim enerji hattının inşaatı tamamlanmamıştır.

İki ülke arasındaki ilişkilerin yönünü incelemek için üst düzey temsilcilerin yabancı (üçüncü) ülkelerde ve uluslararası örgütlerin toplantıları çerçevesinde görüşmelerini karşılaştırmak da önemlidir. Bu aynı zamanda ilişkilerdeki eğilimleri belirlemenizi sağlar. Örneğin, 2018 yılına kadar Ermenistan ve İran İslam Cumhuriyeti temsilcileri çoğunlukla BM toplantıları ve çeşitli BDT ülkelerindeki uluslararası etkinlikler ve toplantılar çerçevesinde ikili toplantılar düzenledi.

2018 yılında Ermenistan'daki “sokak devrimi” nin ardından, Ermenistan'ın Batı yanlısı bir imaj yaratma arzusundan dolayı komşu İranla görüşmelerin bile Batı ülkelerindeki toplantılar

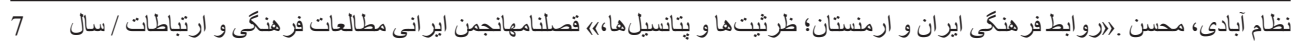

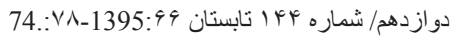

8 Галстян А., «Политические портреты Армении: Роберт Кочарян» [Political Portraits of Armenia: Robert Kocharian]. Last update 11 Февраля, .2013. http://www.yerkramas.org/article/51814/politicheskie-portretyarmenii-robert-kocharyan.

9 نظام آبادى، محسن .»رو ابط فر هنحى اير ان و ارمنستان؛ ظرثيت هاو يتانسيلها،«" 75 
sırasında yapılmasını tercih etme eğilimi oluşmuştur. Örneğin "sokak devrimi” sonrasında Başbakan olan Nikol Paşinyan İran cumhurbaşkanı Hassan Rouhani ile ilk üst düzey toplantısını New York’ta yaptı. Analizler bunun çoğunlukla Ermenistan'ın ABD’ye “İran ile kontrolünüz altında ilişkiler kuruyoruz" mesajını gönderme arzusundan kaynaklandığını gösteriyor. ${ }^{10}$

Dış politikadan sorumlu kurumların ve kişilerin karşılıklı ziyaretlerinin, istişarelerinin sayısı ve seviyesi, hem devletlerarası üst düzey ziyaretlerin düzenlenmesinde, hem de önemli dış politika konularında ilkel anlaşmaların sağlanmasında özel önem taşımaktadır. Devlet başkanlarının ziyaretlerinden önce imzalanacak belgelerin ve toplantıların detaylarının kabul edilmesi özellikle önemlidir. Bu nedenle, dış politikadan sorumlu kuruluşların karşılıklı ziyaretlerinin istatistiksel olarak karşılaştırılması, ikili siyasi ilişkilerin yoğunluğunu belirlemek için önemli göstergelerden biri olarak düşünülebilir. 1991-1997 yıllarında Ermeni Dışişleri Bakanları İran İslam Cumhuriyyetini 5 kez, 1998-2007 döneminde 6 kez ve 2008-2018 döneminde 7 kez ziyaret ettiler. İran İslam Cumhuriyeti'nden Dışişleri Bakanı düzeyinde Ermenistan'a ziyaret sayısı 1991-1997'de 4, 1998-2007'de 4 ve 2008-2018'de 5 kez olmuştur. ${ }^{11}$

Uluslararası kuruluşlarda karar alma sürecindeki pozisyonların çakışması ve önerilen projelerin desteklenmesi de iki ülke arasındaki ilişkilerin düzeyini belirlemek için ana göstergelerden biri olarak düşünülebilir. Ermenistan-İran ilişkilerinin analizi, bu konuya yaklaşımın farklı zamanlarda değiştiğini göstermektedir. Örneğin, Ermenistanın Azerbaycan topraklarını işgali sonucu meydana çıkan Dağlıq Karabağ sorunu Güney Kafkasyanın komşusu olan İranın da güvenliği için bazı tehditler oluşturmuştur. İran İslam Cumhuriyeti'nin Dağlık Karabağ çatışmasına yaklaşımı arabuluculuktan tarafsızlığa, tarafsızlıktan Azerbaycanın haklı konumunun desteklenmesine kadar değişmiştir. Ancak, elbette, bu değişiklikler resmi-diplomatik açıklamalar düzeyinde gerçekleşti. Genel olarak, bağımsızlık ilanından bu yana Ermenistan'ın dış politikasının oluşumu, Rusya ve İran İslam Cumhuriyeti'nin Batı karşıtı cephede bulunması, uluslararası örgütlerde tartışılan birçok konuda iki ülke için örtüşen pozisyonlarla sonuçlandı.

Ermenistan Cumhuriyeti ile İran İslam Cumhuriyeti arasındaki siyasal ilişkileri analiz ederken belirleyebileceğimiz bir diğer indikatör, iki ülke arasında imzalanan belgelerin sayısı ve kapsamı, ayrıca imza sahiplerinin devletin yönetim sistemindeki yeri ve yetkisidir. Doğal olarak, coğrafi olarak komşu olan ve bir dizi konuda benzer ilgi alanlarına sahip ülkeler arasında çok sayıda karşılıklı ziyaret ve tartışma olabilir. Ziyaretlerin ve tartışmaların yararlılığını belirleyen ise anlaşmalar, protokoller ve b. belgelerdir. Sadece imzalı belgelerin sayısı değil, aynı zamanda bunların kapsamı ve imza sahiplerinin devlet yönetimi sistemindeki yeri ve yetkisi de analiz edilmelidir. Bu indikatör üzerine değerlendirme yaparken dikkat etmemiz gerekn önemli husus devletler arasındaki siyasi ilişkilerin ilk aşamasında imzalanan belgelerin (anlaşma ve b.) daha çok sayıda olmasıdır. Doğal olarak tüm alanlarda ilişkilerin kurulması için

10 Elnur Kəlbizadə, Yeganə Baxşıyeva, Oliyar Ozimov. Ermənistan İran İslam Respublikasının Qafqaz siyasətində. (Bak1:MTM İnnovation, 2019), 157-158.

11 "Bilateral Relations with Islamic Republic of Iran,” Last accessed: 30 august, 2019, https://www.mfa.am/en/ bilateral-relations/ir/. 
çok sayıda belgenin imzalanması genellikle erken aşamalarda gerçekleşir. Bu bakış açısından, bu gösterge ile karşılaştırmalar yaparken, sonraki aşamalarda imzalanan belgelerin sayısal avantajına değil, önem derecesine dikkat etmek gerekir. Ermenistan Cumhuriyeti Dış İşleri Bakanlığının sitesinde verilen bilgilere dayanırsak iki ülkenin devlet ve hükümet başkanlarının toplantıları çerçevesinde 1992-1997 yıllarında 19, 1998-2008'de 34, 2009-2011'de 10 belge imzalanmıştır. ${ }^{12}$ Ortalama olarak, ilk kronolojik çerçevede yılda 4 belge, ikinci kronolojik çerçevede yılda 3 belge ve üçüncü kronolojik çerçevede yılda 3 belge bulunmaktadır.

Parlamentolar arası ilişkilerin düzeyi ve imzalanan ikili belgelerin onaylanma (ratification) sıklığı (genliği), ikili siyasi ilişkilerin düzeyini incelemek için indikatörlerden biri olarak da kullanılabilir. Genellikle, diplomatik protokollere uymak zorunda olan devlet ve hükümet başkanları onay için parlamentoya imzalanmış belgeleri gönderiyorlar. Hem İran İslam Cumhuriyeti, hem de Ermenistan Cumhuriyeti'ndeki mevcut siyasi sistem, parlamentonun diğer hükümet kollarından tamamen bağımsız olmasına ve karar vermesine izin vermiyor. İran İslam Cumhuriyeti'nde mesele devlet sistemi ve geleneği ile bağlantılıysa, Ermenistan'daki durum biraz farklıdır. Özellikle 1998-2018 yıllarında Ermenistan'da iktidarı ele geçiren "Karabağ klanı”, parlamentoyu terörizm de dahil olmak üzere çeşitli yollarla önemli ölçüde zayıflatarak cumhurbaşkanına tam bağımlı hale getirdi. Devletlerarası siyasi ilişkilerdeki düşüş veya kriz dönemlerinde, parlamentolar onay sürecini genellikle çeşitli yollarla uzatırlar veya imzalanan belgeleri onaylamazlar. Örneğin, 2018'de Ermenistan'daki sokak gösterileri ve hükümet değişikliklerinden sonra yeni başbakan Nikol Paşinyan'ın İran İslam Cumhuriyeti'ne karşı soğuk bir duruş sergilemesi sebebinden İran tarafı en önemli ortak projelerle ilgili imzalanan bir dizi belgenin onaylanmasını uzatmaya çalıştı. Aynı dönemde iki ülke arasında ticari sirkülasyoda da düşüş yaşand1. O dönemde Theiranproject.com İran İslam Cumhuriyeti’nin ihracat potansiyeli hakkında bir rapor yayınladı. İran İslam Cumhuriyeti resmi gümrük örgütlerinin bilgilerine dayanılarak yayınlanan raporda 2018'in ilk 9 ayında İtalya, İran'dan mal ithal eden ilk ülke olduğu, ikinci ülkenin ise Azerbaycan olduğu açıklandı. Bu dönemde Azerbaycan Cumhuriyeti İran'dan 502 milyon 128 bin 355 dolarlık ürün aldı. Ermenistan İran'dan sadece 160 milyon dolarlık mal ithal etti. ${ }^{13}$ Karşılaştırmak gerekirse, Ermenistan önceki yıllarda İran İslam Cumhuriyeti'nden yapılan ithalatta İtalya'dan sonra ikinci sıradaydı. Doğal olarak, Nikol Paşinyan'ın İran'a karşı olumsuz tutumu ve “ABD korkusu” İran' dan yapılan ithalattaki düşüşün nedenleriydi. Öte yandan, bu durum Ermeni ekonomisinin derin bir kriz içinde olduğunu ve nüfusun satın alma gücünün keskin bir şekilde düştüğünü göstermektedir.

Ermenistan Başbakanı Nikol Paşinyannın Şubat 2019'da İran İslam Cumhuriyeti'ne ziyaret programında bile, İslam Cumhuriyeti ile imzalanmış belgelerin onay konusunun tartışılması

12 "Bilateral Relations with Islamic Republic of Iran," Last accessed: 30 august, 2019, https://www.mfa.am/en/ bilateral-relations/ir/.

13 Rabil KӘTANOV, "Paşinyanın İran səfəri və doğrulmayan ümidlər.” Son yenilənmə tarixi: 02 Fevral, 2019. https://azertag.az/xeber/Pasinyanin_Iran_seferi_ve_dogrulmayan_umidler-1253526. 
kilit konulardan biri olarak tanımland $1 .{ }^{14}$ Ermenistan bunun yerine Avrasya Ekonomik Birliği ile İran İslam Cumhuriyeti arasında imzalanan bir serbest ticaret anlaşmasının parlamentolarının erken onaylanmasına destek sözü verdi. Bu konu Nikol Paşinyan'ın İran İslam Cumhuriyeti İslami Şura Meclisi Başkanı Ali Larijani ile yaptığı toplantıda tartışıldı. O zaman, Avrasya Ekonomik Birliğinde Ermenistanın başkanlık sürecinin başlaması İran İslam Cumhuriyeti’nde bu firsatı kullanma ve süreci hızlandırma arzusu yarattı.

Devletlerarası ilişkileri analiz ederken, hükümetlerin eylem planlarına diğer ülkeyle ilgili olarak atılacak adımları dahil edip etmedikleri ile önemli göstergedir. Örneğin, Ermenistanda Başbakan Tigran Sarkisyan hükümetinin 2008-2012 programında İran İslam Cumhuriyeti ile ilişkilerle ilgili herhangi bir konuya değinilmedi. ${ }^{15} 2016$ ' da Ermenistan'da kabul edilen hükümet programı, İran İslam Cumhuriyeti ile ilişkilerle ilgili iki noktaya değinildi. Programın "Enerji Altyapısı ve Doğal Kaynaklar" başlıklı bölümünün "Sürdürülebilir Ekonomik Kalkınma" isimli alt bölümünde, 2019'da Ermenistan ve İran arasında yüksek voltajlı bir elektrik hattı inşa edilmesinden bahsedildi (paragraf 8). ${ }^{16}$ "Dış Politika, Diaspora, Savunma, Güvenlik, Acil Durumlar, İnsan Hakları, Adalet ve Yolsuzlukla Mücadele” başlıklı bölümde dış politika önceliklerinden biri olarak İran ve Gürcistan gibi komşu ülkelerle ilişkilerin geliştirilmesi gösterildi.

\section{Sonuç}

Sonuç olarak, yukarıdaki analiz, indikatör yönteminin modern koşullarda devletlerarası ilişkilerle ilkili bilimles çalışmalarda başarıyla uygulanabileceğini kanıtlamaktadır. Sadece bu durumda devletlerarası ilişkilerin gelişimi, istikrarı veya düşüşüyle bağlantılı olarak ortaya konan tezler bilimsel olarak objektif olarak kabul edilebilir. Burada birkaç noktanın açıklığa kavuşturulması gerekiyor. Her şeyden önce, devletlerarası ilişkilerin hareketinin doğasını belirleyen göstergeler olmalıdır (gelişme ve düşüş). İkinci olarak, bu göstergeler, belirli bir zaman dilimi içinde devletlerarası ilişkilere uygulanmalıdır. Üçüncüsü, alınan göstergelerin değerlendirilmesi, araştırmacının aynı göstergeleri başka bir zaman diliminde tanımlananlarla karşılaştırma firsatı bulduğunda, hareketin doğasını- ilerleme ve düşüş gösterebilir.

Hakem Değerlendirmesi: Dış bağımsız.

Çıkar Çatışması: Yazar çıkar çatışması bildirmemiştir.

Finansal Destek: Yazar bu çalışma için finansal destek almadığını beyan etmiştir.

Peer-review: Externally peer-reviewed.

Conflict of Interest: The author has no conflict of interest to declare.

Grant Support: The author declared that this study has received no financial support.

14 “Большие ожидания от секретной повестки: с чем Пашинян вернется из Ирана.” [Great expectations from the secret agenda: what will Pashinyan return from Iran with]. Last updated 19 February, 2019. https:// ru.armeniasputnik.am/politics/20190219/17378689/bolshie-ozhidaniya-ot-sekretnoj-povestki-s-chem-pashinyanvernetsya-iz-irana.html.

15 Republic of Armenia Government Program. (Yerevan: SAMARK Printing House, 2008), 55.

16 Programme of the Government of the Republic of Armenia. (Yerevan, October 2016),23. 


\section{Kaynakça/References}

1. Armeniasputnik, "Большие ожидания от секретной повестки: с чем Пашинян вернется из Ирана." [Great expectations from the secret agenda: what will Pashinyan return from Iran with]. Last updated 19 February, 2019. https://ru.armeniasputnik.am/politics/20190219/17378689/bolshie-ozhidaniya-otsekretnoj-povestki-s-chem-pashinyan-vernetsya-iz-irana.html.

2. ARXINA, Qovluq 6, v. 26.

3. Azərtac. KəTANOV, Rabil. "Paşinyanın İran səfəri və doğrulmayan ümidlər." Son yenilənmə tarixi: 02 Fevral, 2019. https://azertag.az/xeber/Pasinyanin_Iran_seferi_ve_dogrulmayan_umidler-1253526.

4. KӘLBİZADӘ, Elnur., BAXŞIYEVA, Yeganə., OZIMOV, Oliyar. Ermənistan Íran İslam Respublikasının Qafqaz siyasatində. Bak1: MTM İnnovation, 2019.

5. Mfa.am. "Bilateral Relations with Islamic Republic of Iran". Last accessed: 30.08.2019. https://www.mfa. am/en/bilateral-relations/ir/.

6. Programme of the Government of the Republic of Armenia. Yerevan. October 2016.

7. Republic of Armenia Government Program. Yerevan: SAMARK Printing House, 2008.

8. Yerkramas.org. ГАЛСТЯН А., «Политические портреты Армении: Роберт Кочарян» [Political Portraits of Armenia: Robert Kocharian]. Last update 11 Февраля, .2013. http://www.yerkramas.org/article/51814/ politicheskie-portrety-armenii-robert-kocharyan.

9. ВЛАСОВА, Мария. «Прогнозирование в разведке: метод индикаторов в современных условиях» [Intelligence forecasting: a method of indicators in modern conditions], Вестник РУДН, серия Международные отношения, том 15/3 (сентябрь 2015): 34-42.

10. МИХАЙЛОВИЧ, Игорь. Применение математических методов при исследовании системы международных отношений с использованием функииональных пространств [The use of mathematical methods in the study of the system of international relations using functional spaces]. Москва, 1997.

11. ТИМОФЕЕВА, Марина. “Опыт политического прогнозирования в США и России” [“Political Forecasting Experience in the USA and Russia"]. Автореферат диссертации на соискание учено степени кандидата политических наук. Санкт-Петербургски Государственный Университет, 2005.

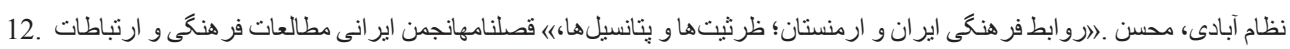

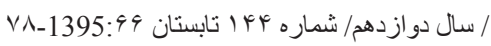

[NEZAMABADİ, Mohsen. "Cultural Relations between Iran and Armenia; Possibilities and Potentials,» Iranian Journal of Cultural Studies and Communication / Twelfth Year / No. 144 Summer 2016: 66-87] 
